\title{
Multimodal Definition: The Multiplication of Meaning in Electronic Dictionaries
}

\author{
Xiqin Liu, School of Foreign Languages, \\ South China University of Technology, China and \\ Guangdong University of Foreign Studies, China \\ (flxqliu@scut.edu.cn)
}

\begin{abstract}
With the popularity of electronic dictionaries, multimodality plays an increasingly important role in lexicography. To broaden the horizons of e-dictionary definitions, this article argues for the establishment of a new term, multimodal definition, as a key component of multimodal lexicography. This term integrates verbal definitions and the complementary multimodal resources from a holistic viewpoint of meaning. In a multimodal definition, a dynamic meaning ecology can be formed, with two critical variables functioning, (semiotic) mode selection and intermodal synergy. In this ecology, meaning expressed verbally can be multiplied in four dimensions: content, form, space and time. Future directions for research are discussed, including dictionary user studies and multimodal corpora. The findings of this article shed light on the construction of a theoretical model for e-lexicography which remains an urgent task in the ongoing digital revolution.
\end{abstract}

Keywords: MULTIMODALITY, MULTIMODAL DEFINITION, MULTIMODAL LEXICOGRAPHY, E-DICTIONARY, MODE SELECTION, INTERMODAL SYNERGY

Opsomming: Multimodale definisie: Die verveelvoudiging van betekenis in elektroniese woordeboeke. Met die oplewing in elektroniese woordeboeke speel multimodaliteit ' $n$ toenemend belangrike rol in leksikografie. Om die bestek van e-woordeboekdefinisies te vergroot, word daar in hierdie artikel geargumenteer ten gunste van die vestiging van 'n nuwe term, multimodale definisie, as 'n sleutelkomponent van die multimodale leksikografie. Hierdie term word vanuit 'n holistiese betekenisoogpunt gewy aan die integrering van verbale definisies en die komplementêre multimodale bronne. In 'n multimodale definisie kan 'n dinamiese betekenisekologie geskep word waar twee kritiese veranderlikes funksioneer, (semiotiese) modusseleksie en intermodale sinergie. In hierdie ekologie kan betekenis wat verbaal uitgedruk word, in vier dimensies verveelvoudig word: inhoud, vorm, ruimte en tyd. Toekomstige navorsingsrigtings, insluitende woordeboekgebruikerstudies en multimodale korpora, word bespreek. Die bevindings van hierdie artikel werp lig op die samestelling van 'n teoretiese model vir e-leksikografie wat 'n dringende taak in die voortgesette digitale revolusie bly.

Sleutelwoorde: MULTIMODALITEIT, MULTIMODALE DEFINISIE, MULTIMODALE LEKSIKOGRAFIE, E-WOORDEBOEK, MODUS-SELEKSIE, INTERMODALE SINERGIE 


\section{Introduction}

In the new era of digital media, electronic dictionaries (e-dictionaries) are booming as a common tool of language learning and use. In the field of e-lexicography, such core notions as multimodality and meaning representation have aroused the interest of researchers.

As "the normal state of human communication" (Kress 2010), multimodality is defined as the diverse ways in which multiple semiotic resources (1anguage, visual images or sound, etc.) are co-deployed and co-contextualized in the making of a text-specific meaning (Thibault 2001). The collection of different semiotic modes (textual, visual, audio, spatial, etc.) can determine how an audience perceives information. Therefore, multimodality is crucial for meaning representation in dictionaries, especially in e-dictionaries.

As the heart of meaning representation in a dictionary, definition plays a key role in stating or explaining the meaning of a word or phrase. This term, if used as a countable noun, can also refer to the product of the process of defining, as indicated under the entry of definition in Oxford Advanced Learner's Dictionary of Current English (the 6th edition, 2000):

\section{definition}

noun

1. $[\mathrm{C}, \mathrm{U}]$ an explanation of the meaning of a word or phrase, especially in a dictionary; the act of stating the meanings of words and phrases

To deepen our understanding of meaning representation in e-dictionaries, we propose the term multimodal definition under the umbrella of multimodal lexicography proposed by Lew (2010). It is tentatively defined as "(the act of) meaning explanation of a word or phrase with multimodal devices for achieving better defining effect than language does alone, especially in an edictionary". Meanings explained by written language are called verbal definitions in this research. By viewing verbal definitions and the complementary multimodal resources as an organic whole and combining them into one cover term, the close relationship between them would be valued, and the horizons of e-dictionary definitions could be expanded.

So a holistic view of meaning is taken in this article. On the one hand, following the theory of "meaning as use" (Wittgenstein 1953), meaning and usage are inseparable, and "in a living language vocabulary and grammar do not have their own independent existences" (Tarp 2008: 135). On the other hand, cognitive findings tell us that linguistic information of a word or phrase is blended with encyclopedic information. In brief, meaning is of multiple facets integrated into a whole.

In the above-mentioned context, this article argues for the establishment of the notion of multimodal definition and aims to investigate the mechanism and function of multimodal definitions in terms of meaning representation. Within 
a unified framework of multimodal lexicography (Lew 2010) and multimodal discourse analysis ${ }^{1}$ from a systemic functional perspective (O'Halloran 2008), the present study was guided by the following research questions:

1) Is the concept of multimodal definition necessary in practice and theory?

2) What are the dominant variables operating in the semantic ecology of multimodal definitions?

3) In which dimensions can meaning be multiplied in this ecology?

\section{Literature review}

\subsection{Limitations of verbal definitions}

Verbal definitions are of various types, ranging from the traditional genus-differentia format to the recent full-sentence definition (Atkins and Rundell 2008: 416-441). However, many studies show that such a variety still can't ensure that verbal definitions are effective enough to meet the personal needs of dictionary users (Zhang 2002: 133-145). Problems like circularity, inaccuracy, over-defining, redundancy or lack of necessary pragmatic and cultural information can be found even in leading dictionaries (Zhang 2015: 79-82). The problem of inaccuracy seems to be intensified by the controlled defining vocabulary in learner's dictionaries and children's dictionaries (Feng 2009: 153-154). Furthermore, the lexicographic treatment of words expressing abstract relations, such as that of prepositions, is still unsatisfactory in many dictionaries (Coffey 2006; Lew 2010).

Such problems often seem unavoidable. For one thing, meaning is often subtle, multiple and even capricious so that it is hard to fully grasp it. For another, a verbal definition is, by its nature, a rather abstract construct (Atkins and Rundell 2008: 454), whether it is at the same semiotic level (periphrastic synonymy) as the defined or at the level of a constructed metalanguage. So there are many cases where the full sense of a difficult concept only becomes clear with a graph or video clip illustrating its contextual features and usage (cf. ibid: 454). Definition devices beyond words often complement verbal definitions and can even provide inspirations for lexicographers to optimize the verbal information. For example, solutions to the above problems, like using schematic graphs to illustrate the meaning of prepositions advocated by Adamska-Sałaciak (2008), often entail the use of multimodal devices, especially in e-dictionaries.

\subsection{Meaning representation problems in e-dictionaries}

In terms of meaning representation, many studies show there is much room for improvement in current e-dictionaries. Electronic dictionaries are often regarded as inferior in quality (Tono 2009: 48; Chen 2010), and they are still to a large extent presented in a form similar to printed formats, so the potential is still under-utilized (Prinsloo 2012). Some scholars complain about the unimagi- 
native use of the new powerful technologies in specialized online dictionaries (Caruso 2014; Fuertes-Olivera and Tarp 2014). Many popular online bilingual dictionaries translate in a fairly primitive way without information or labels to indicate register differences or restrictions on use (Nesi 2012). Many local e-dictionaries in East Asia, like the widespread Jin Shan $\mathrm{Ci} \mathrm{Ba}$ in China, are of poor quality, as evidenced by mistranslations and lack of information on usage (Zhang 2004; Nesi 2012). As shown by Kurtz (2012), there is inaccurate information in You Dao, a very popular e-dictionary in China.

In short, researchers find that too many lexicographic e-products were developed without any influence from innovative theoretical suggestions, and as a result current e-dictionaries too often do not live up to the expectations of their users (Gouws 2014). Therefore, a theoretical anchor point is needed to enable a breakthrough in improving e-dictionary definitions.

\section{Rationale for proposing multimodal definition}

\subsection{Practical rationale}

As illustrated above, the limitations of verbal definitions and the meaning representation problems in e-dictionaries justify the necessity of a new horizon of defining in the digital revolution. The establishment of the notion of multimodal definition is expected to help solve those problems by arousing lexicographers' attention to the multimodality of e-dictionary definitions and awareness of how definitions can be improved both verbally and non-verbally. In fact, the multimodality of the definitions in e-dictionaries is quite different from that in paper dictionaries. The former involves many more complex factors for consideration in lexicographical practice.

Furthermore, since the e-dictionary is often used as a vocabulary learning tool by language learners (Nesi 2010), they may depend even more on edictionaries for definitions in the new era of multiliteracies. The widespread use of e-dictionaries embedded in multimodal texts has intensified the urgent need to solve the current problems in meaning representation. A conceptual expansion in defining theories may give fresh impetus to change at this watershed of e-dictionaries. As Amsler (2012) warns, fundamentally, electronic dictionaries "think" of themselves as print dictionaries being offered via electronic access, and this is a very limiting vision.

\subsection{Theoretical rationale}

In essence, the poor quality of e-dictionaries can be traced to the lack of theoretical models which lexicographers could rely on. The golden opportunity to lead the way in devising models for e-dictionaries was unfortunately not utilized sufficiently by metalexicographers (Gouws 2014). Where practical lexicog- 
raphers did utilize lexicographic theory, it often was a version that had been devised for printed dictionaries.

So it is necessary to devise theoretical models for e-dictionaries that focus on critical areas like the data to be included in these dictionaries, the structures to present and accommodate the data, and the way they should respond to the needs of their target users (Gouws 2014). In fact, all these areas are closely related to the meaning representation and multimodality of e-dictionaries. What's more, the recent findings in multimodal discourse analysis (O'Halloran 2011: 120), such as intermodal relations, can shed light on how to construct theoretical models, but those findings have not been fully exploited by lexicographers.

Lew (2010) proposed the framework of multimodal lexicography by illustrating various modes of meaning indication in e-dictionaries and showing how they can complement verbal definitions. With a solid base in e-lexicography, his research gained support from many researchers, such as Yang (2012) and Luo (2012). However, multimodal lexicography covers too broad a range and a clear picture of its structure and mechanism is still lacking. It is of great significance to investigate one of its key components, multimodal definition, especially from the perspective of multimodal discourse analysis.

After all, the concepts of "multimodality" and "definition" both focus on meaning and meaning-making. Theoretically they can be integrated naturally across discipline boundaries between multimodal discourse analysis and lexicographical definition.

In brief, only when the status of multimodal definition is recognized as a major component of multimodal lexicography, can its nature be fully understood and theoretical models and guiding principles be established for lexicographers.

\section{The semantic ecology of multimodal definitions}

\subsection{Overview of the semantic ecology}

From a holistic viewpoint, the meaning system of a multimodal definition can be compared to an ecology and it is characterized by complexity, diversity and dynamicity. There are interactions among its members, as well as cooperation and competition. Its components or communities are conceptually linked together as an integrated whole in a hierarchy. A close look at the components of this semantic/meaning ecology can help understand e-dictionary definitions.

In the trichotomy of multimodal devices proposed by Lew (2010), there are three categories: written language, audio presentation of the verbal elements including human voice recordings and synthesized speech, and other devices. Considering the differences between paper dictionaries and electronic ones, the first category is labeled as the verbal mode/definition, and the last two are non-verbal ones in this study.

The third category of Lew (2010) can be further divided into five types: 
1) audio (recordings of non-linguistic sounds);

2) visual (static pictorial illustration, photographs, graphs, silent animations, tables, icons, typography etc.);

3) audio-visual (animations and video clips);

4) spatial (framing ${ }^{2}$, hyperlinks, floating tips ${ }^{3}$, sense menus, pop-up windows etc.) and

5) other affordances to be realized (e.g. tactile or gustatory modes).

All these members coexist in a semantic ecology tentatively illustrated by Figure 1.

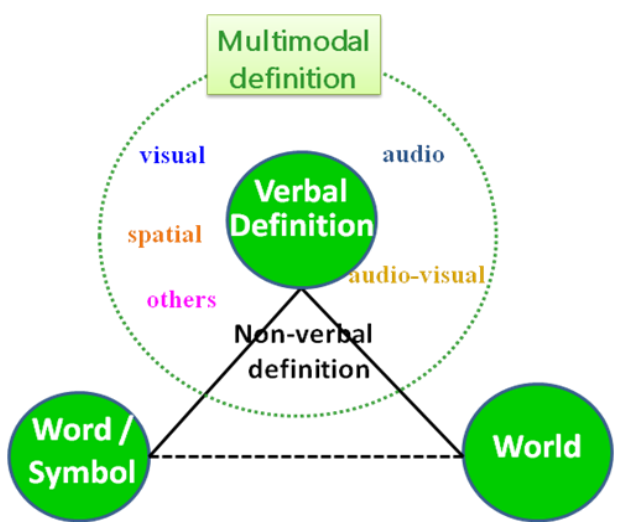

Figure 1: Semantic ecology of multimodal definitions

The top of Figure 1 shows the relationships between the two components of a multimodal definition: verbal and non-verbal, with the former at the core and latter on the periphery. In this sense, the latter can "wrap" and "enlarge" (multiply) the meaning expressed by the former.

Following the semantic triangle of Ogden and Richards (1923), there are two relating ecologies: the word/symbol and the world. From a cognitive perspective, a non-verbal definition can shorten the distance between the verbal definition and the defined word or phrase, serving as a link between the verbal definition and the outside world, hence better defining effect is likely to be achieved.

\subsection{Dominant variables of the semantic ecology}

Based on Multimodal Discourse Analysis (Kress and Van Leeuwen 1996; Royce 1998, 2007; O'Halloran 2008; Chan 2011: 144-165) from a Systemic Functional perspective (Halliday 1985), two dominant variables are found to be operating in a robust semantic ecology of the multimodal definitions: mode selection and intermodal synergy. The first means the choice of semiotic modes, and the latter refers to the cooperation and interaction among different modes. 


\subsubsection{Mode selection}

Mode selection is a function of many variables, such as the purpose of compilation, number of languages involved, type of medium used, target users, items to be defined and semiotic modal resources available. The purpose of a dictionary can be language comprehension or production. It can be monolingual, bilingual or multilingual. Its medium can be a desktop, laptop, tablet or mobile phone, etc. Its target users can be children or adults, foreign language learners or native speakers. The items to be defined can be concrete or abstract, commonly-used or rare. Additionally, modal resources are different from each other in how to represent meaning, and a good multimodal corpus should give definers a wide range of options to choose from.

Most important of all, it is the correspondence between the nature of the item to be defined and the characteristics of a semiotic mode that plays an essential role in mode selection. We have some tentative suggestions about the correspondence while a systematic study of mode selection is still to be conducted.

First, there is usually an audio-audio or visual-visual match between the item to be defined and the mode for meaning explanation. For example, if the word is related to some sound, an audio recording of that sound is of course a good choice for complementing its verbal definition.

Second, there can be a concrete-concrete or abstract-abstract match between them. However, an abstract-concrete match may be more effective for young target users of the dictionary, and a concrete-abstract match may be enough for adult users if storage space is limited (as in a mobile phone dictionary). If an abstract process is to be defined, a flow chart alone may be enough for adults, but an animation or video clip is often more effective for children.

Third, typicality is one of the most important factors to be considered in mode selection. Non-verbal modes should provide the most typical context of language use for instantiation. This is crucial for learner's dictionaries, following the Theory of Family Resemblance (Wittgenstein 1953) and the Prototype Theory (Rosch 1973). For instance, a robin may be a prototype for the headword "bird", so a picture of a robin is preferable to those of other kinds of birds. When defining a verb, the most typical semantic roles/arguments are often desirable or even essential. Taking "wash" as another example, a scene of washing clothes or hands is preferred to one of washing something rare.

Fourth, the differences between semiotic modes (especially language vs. images) should be taken into account. A verbal text unfolds over time in a dynamic, sequential way and language has a rich potential for the construal of temporal deixis, sequencing, location phasing and aspect, and this is in contrast with the instantaneous holistic apprehension of an individual image and the corresponding potential of the visual semiotic for nonsequencing spatial and comparative relationships (Painter et al. 2013: 133).

Last, mode selection should be very careful as some modal resources may 
impede the learning process of users if not properly designed or chosen. There is evidence that users who viewed animations for the target entries had significantly lower vocabulary retention rates than those who ignored the animations (Lew and Doroszewska 2009).

\subsubsection{Intermodal synergy}

In a robust semantic ecology, the synergy between different semiotic modes is critically important, especially the text-image (verbal-visual) interface which is in the heart of multiliteracies.

Identifying cohesive links and examining the logical relations in ideational meaning that extend across semiotic modes may help us gain an in-depth understanding of intermodal synergy. In this study, Chan's (2011: 144-165) model of intermodal relations has been modified to suit e-dictionary definitions. Based on her framework, intermodal synergy falls into two categories: concurrence and complementarity (see Figure 2), each of which can be further divided into four types, forming a hierarchical system.

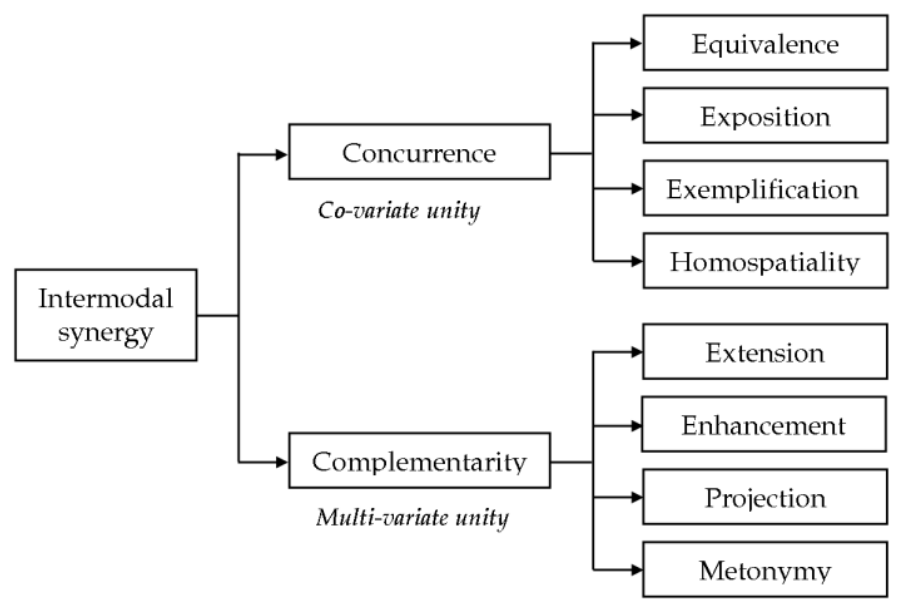

Figure 2: Toward intermodal synergy in multimodal definitions

\subsubsection{Intermodal concurrence}

The (intermodal) concurrence or agreement, where meanings across modes are similar, is one of co-variate unity (ibid: 144-165). Concurrence may entail some form of redundancy across modes, but this is not a simple inter-modal duplication of meaning (Unsworth 2006). It includes four basic types: equivalence, exposition, exemplification and homospatiality ${ }^{4}$.

Equivalence of meaning across semiotic modes means that they are mutu- 
ally identifying, following Gill (2002). Being most common in both paper and electronic dictionaries, equivalence can be partial or full. For example, the verbal definition of "napkin" is accompanied by the (partially) equivalent picture in the online Longman Dictionary of Contemporary English (http://www. ldoceonline.com/dictionary/napkin) (see Figure 3).

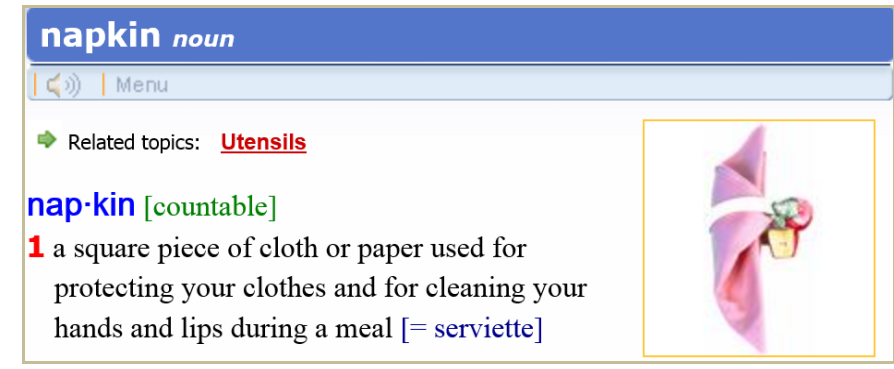

Figure 3: Napkin in LDOCE

Exposition means that, by expressing the same meaning in different ways, different modes reinforce each other. An example (see the entry of lever in Figure 4) is taken from the online Merriam-Webster Visual Dictionary (http://visual. merriam-webster.com/science/physics-mechanics/lever.php). The picture is not just an equivalence of the word "lever", but also a vivid illustration of the mechanism of the equipment stated in the verbal definition, with arrows pointing various directions.

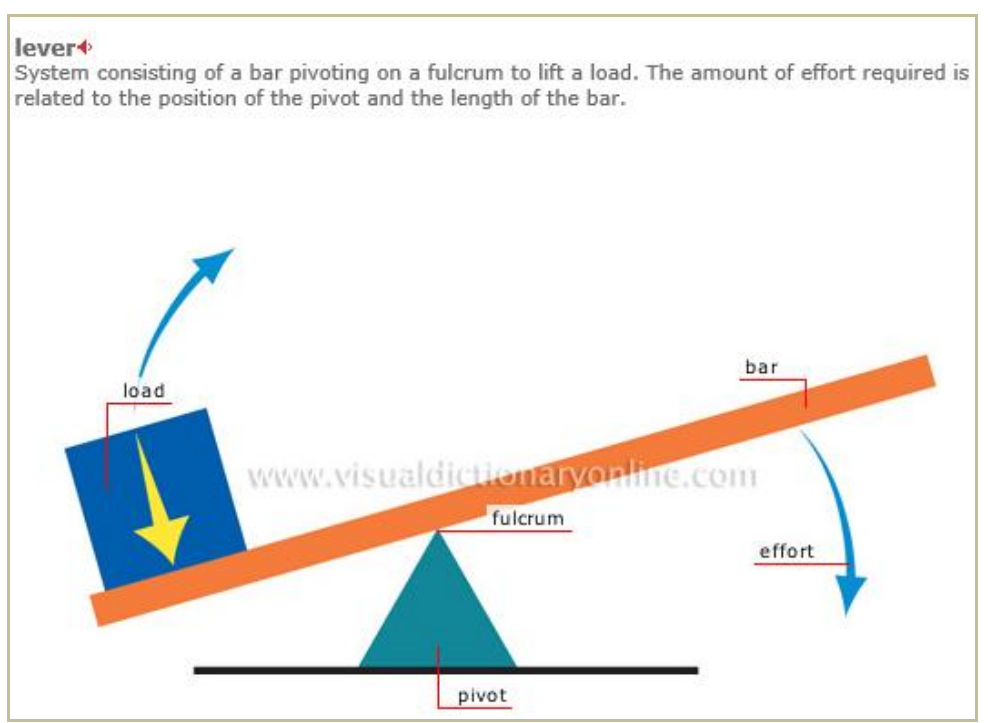

Figure 4: Lever in MWVD 
Exemplification refers to a case in which a non-verbal mode exemplifies the verbal, giving an example to make it clear. The modes represent different levels of generality (Martinec and Salway 2005), and are of a class-member relationship. An example taken from Oxford Learner's Dictionary is the charts (bar, flow and pie) under the entry of flow chart (http://www.oxfordlearnersdictionaries. $\mathrm{com} /$ definition/english/flow-chart?q =flow+chart). Figure 6 is a pop-up window emerging when the user clicks the icon in the lower right corner of Figure 5.

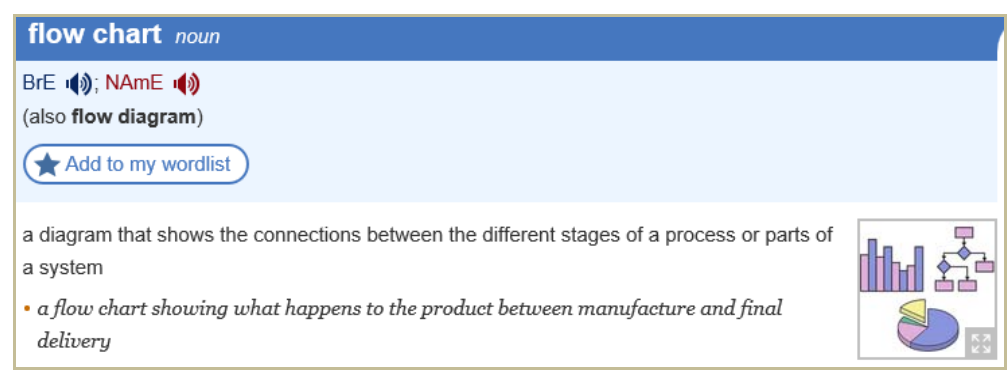

Figure 5: Flow chart in OLD

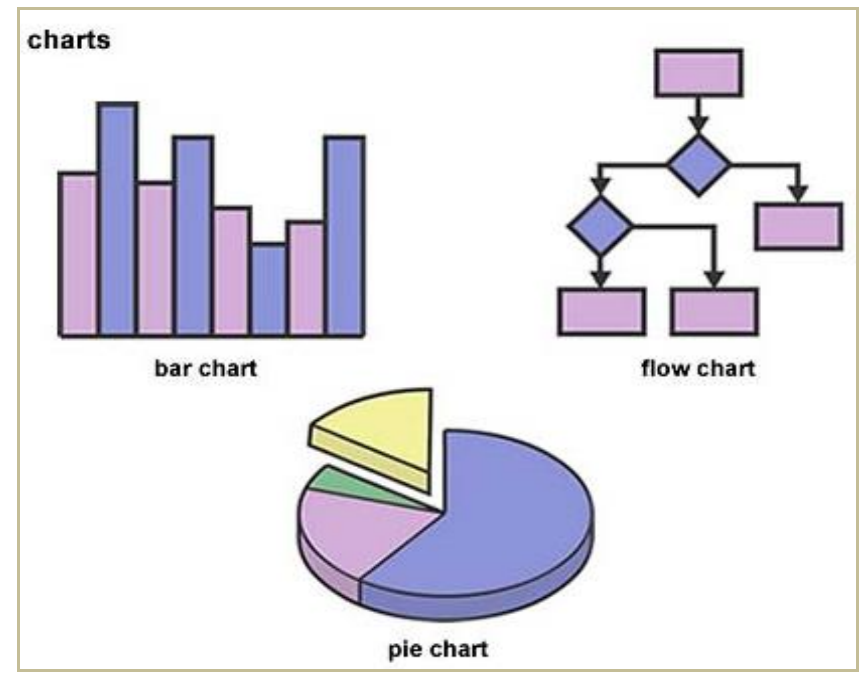

Figure 6: Charts in OLD

Homospatiality means that different semiotic modes co-occur in one spatially bonded homogenous entity (Lim 2004; Unsworth 2006). An example of homospatiality is the word "arc" arranged in the shape of an arc, or the word "blue" printed in the color blue. It is rare in dictionaries. The following picture accompanying the linguistic meaning of the word "onion" may be regarded as a vari- 
ety of homospatiality (cited from Unsworth 2006), the picture and the word overlap each other, and the latter is in purple, a prototypical color of onions.

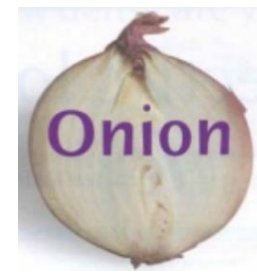

Figure 7: Homospatiality of onion

\subsubsection{Intermodal complementarity}

The (intermodal) complementarity, where meanings across modes are different but complement each other, is oriented towards multivariate unity (Chan 2011: 144-165). In Chan's (ibid: 144-165) model, it is divided into three basic types: extension, enhancement and projection. But we have found a new type, metonymy, in multimodal definitions. These distinct but interrelated types are respectively illustrated as follows.

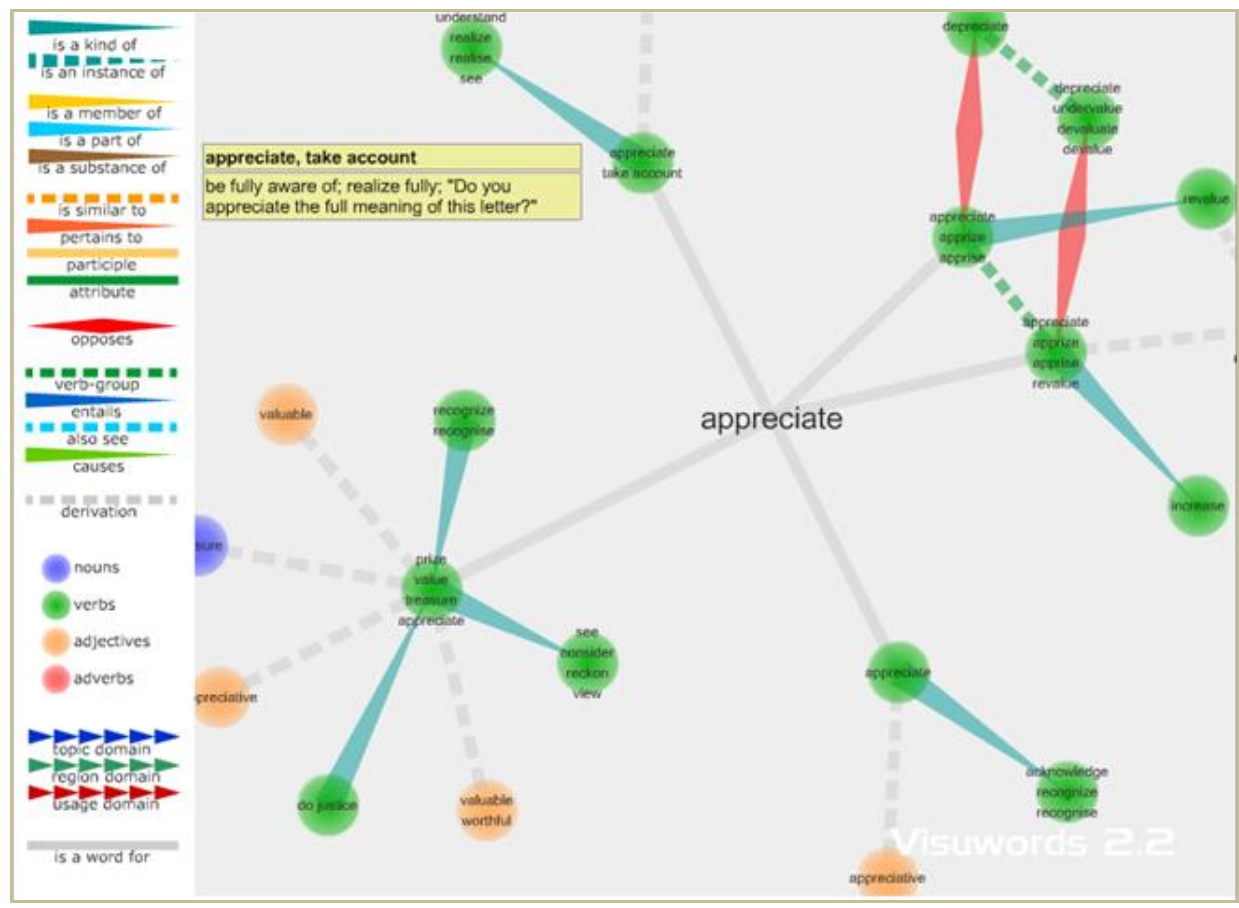

Figure 8: A floating quasi-3D graph for appreciate in VISUWORDS 
Extension means that meanings additional to those in one mode are represented in another (Unsworth 2006, 2008). New, related information is added. For example, images might illustrate the inherent relationship between the defined item and related ones in the semantic network. A case in point is a floating quasi-3D graph (see Figure 8), demonstrating the sense relations for the entry of appreciate in the VISUWORDS interface (http://www.visuwords. com/, cf. Lew 2010).

Enhancement means that one mode provides meanings which expand another spatially, temporally or causally, etc. The image might depict the end result of a process described in the verbal text (Unsworth 2006). If a word has negative connotations or semantic prosody, like "funeral", the audio recording can carry an unhappy tone to achieve enhancement.

Projection originally means the use of speech or thought bubbles, but in edictionaries, the floating tips are the major type of projection, which facilitates fast access to meaning. In VISUWORDS (see Figure 8), the verbal definition emerges when the mouse rests on any word in the graph, and such dynamicity enables more interactions between the user and the dictionary. So is Visual Thesaurus (http://www.visualthesaurus.com).

Metonymy, if cross-modal or multimodal, refers to a contiguity relationship between different modes, especially a part-whole one. It has mostly a referential or predictive function. As an example, the entry of wild is taken from LDOCE (http://www.ldoceonline.com/dictionary/wild_1). In Figure 9, the picture of a tiger is used to describe the adjective "wild", since being wild is a dominant feature of a tiger and this animal is a prototype symbolizing wildness. The user's cognitive process involves four major steps: the tiger head, the whole tiger, a typical wild animal/thing and the nature of being wild. It is metonymy that facilitates every transition between consecutive steps. The image of a tiger head is metonymic for it represents the whole body of the tiger. The tiger is also metonymic since it stands for any wild animal/thing. So is the typical wild animal/thing as it symbolizes the quality of being wild.

\begin{tabular}{l}
\hline Wild $^{\mathbf{1}}$ adjective \\
\hline (द)) Menu \\
$\Rightarrow$ Related topics: $\underline{\text { Cards, Nature }}$ \\
wild \\
1 PLANTS/ANIMALS [usually before noun] living \\
in a natural state, not changed or controlled by \\
people [ $\neq$ tame]:
\end{tabular}

Figure 9: Metonymy of wild in LDOCE 
The above may not be a complete list of the logical relationships between verbal and non-verbal modes in multimodal definitions. But what seems certain is the relationships are unidirectional in most cases because the verbal mode is regarded as central and non-verbal modes are intended to complement or reinforce it. Where decoding linguistic meaning was unsuccessful or only partially successful, dictionary users would rely on non-verbal modes to support their interpretation. Complementary items were found to be more difficult than those where there was concurrence of meaning across modes, and among concurrent relationships, exposition was more difficult than equivalence (Chan 2011: 144-165). So equivalence is most recommended for dictionaries designed for elementary language learners and/or dictionary users.

\section{Dimensions of meaning multiplication}

In the semantic ecology of a multimodal definition, meaning expressed verbally can be enriched, expanded or multiplied by the combination of verbal and non-verbal modes (cf. Royce 1998; Lemke 2002; O'Halloran 2008) in various dimensions. The concurrence or complementarity (Chan 2011: 144-165) between different modes amplifies meaning. For a detailed analysis from a systemic functional perspective, we employ the widely accepted framework of three metafunctions of the semiotic system: ideational, interpersonal and textual (Halliday 1985). They can be respectively realized by the dimensions of content, form and space in multimodal definitions. A fourth dimension, time, is added for a longitudinal view (see Figure 10).

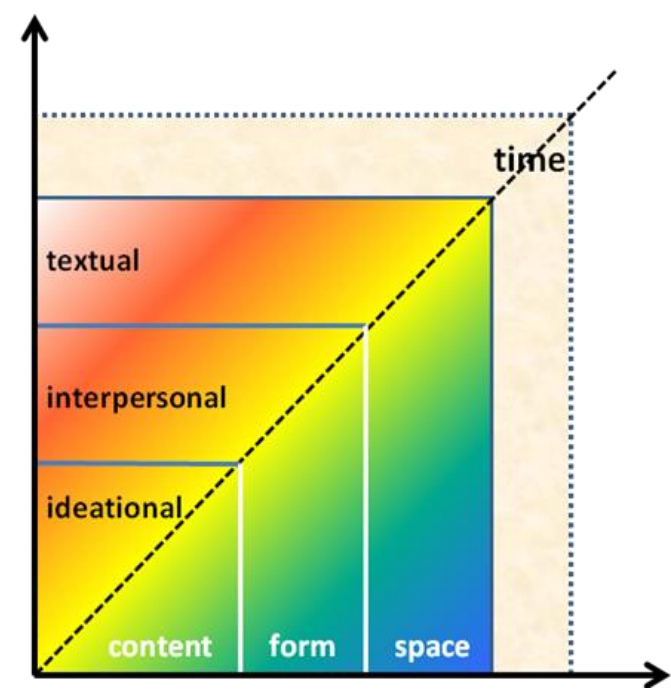

Figure 10: Meaning multiplication by multimodal definition 


\subsection{Content}

The ideational metafunction is the most important for the defining of dictionaries because it is closely related to the content of meaning. Concerning the material reality, ideational structures construct the nature of events, the objects and participants, and the circumstances (Unsworth 2006) which can be better represented by multimodal devices than language alone does, enriching the content of meaning in a dictionary.

With multimodal devices, e-dictionaries often have the ability of showing more senses of a word and sense relations between words than their paper versions when necessary. This is an explicit and direct augmentation of meanings.

Implicitly, e-dictionaries are often more powerful in showing the characteristic co-text and context of a word/phrase which constitute part of the meaning. In such circumstances, encyclopedic and pragmatic meanings can be easily added. For instance, in bilingual dictionaries, when some culture-specific or confusing words/phrases are difficult to explain by language, proper multimodal devices are likely to vividly clarify or accurately represent the opaque meaning expressed by words, such as pictures showing the differences between "Roman nose" and "Grecian nose", and those between "in front of" and "in the front of". As elaborated above, meaning can be multiplied in the interactions between different modes, especially through intermodal concurrence and complementarity which add to the meaning of language.

Last, new media enable more interactions between the user and the e-dictionary (compiler/writer), which is part of the process of making meaning and has the potential of enriching meaning. In this sense, the ideational metafunction of multimodal definition is interwoven with its interpersonal metafunction.

\subsection{Form}

Interpersonally, a dictionary entry constructs the compiler/writer as a giver of information and the user as a receiver. In terms of an e-dictionary, the user often has more opportunities to probe meaning information than he does when passively receiving it from a printed one. Its multimodality can actually change the interpersonal relationship. The interpersonal metafunction is mainly realized by the forms of expressing meaning and it is often embodied by userfriendliness of dictionaries. Interpersonal resources construct the nature of relationships among addressers and addressees, and viewers and the viewed. Besides language, visual, audio and spatial modes provide diverse ways of showing meaning. The presentation of lexicographical data can take many different forms, depending on the needs of specific users and the situations with which they are confronted (Tarp 2008).

As electronic dictionaries start to exploit the opportunities of the medium more imaginatively, they could well offer users a range of defining options, like 
word clouds and semantic networks. Figure 11 shows the word cloud "deduction" in Cambridge Dictionaries Online (http://dictionary.cambridge.org/dictionary/ british/deduction), where the size, color and font etc. of each word all represent meaning.

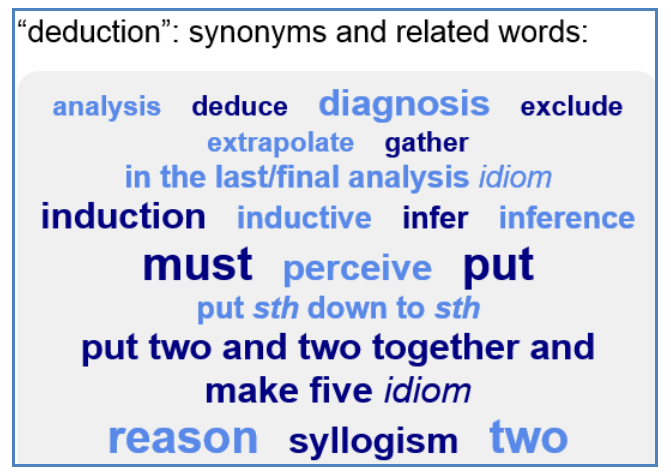

Figure 11: Word cloud of deduction in CDO

Other new affordances of the digital era are gaze-contingent systems utilizing modern eye tracking (Bulling and Gellersen 2010) and a system like Google Glass (Lew and De Schryver 2014). With the development of digital technology, more modes like the gustatory might be realized. For instance, the smell could be transmitted to the user via the internet someday. The diversity of the forms of such multimodal resources is likely to help improve the user-friendliness of a dictionary if specific user needs can be considered and satisfied.

\subsection{Space}

The textual metafunction is mainly realized by the space arrangement in multimodal definitions. Textual meanings concern the distribution of the information value or relative emphasis among elements of the multimodal text (cf. Kress and Van Leeuwen 1996: 175-214; Unsworth 2006).

Generally speaking, a dictionary entry locates the headword as the "Theme" or given information, and the "Rheme" or new information is the following verbal definition. If the verbal definition is complemented by non-verbal resources, it may become the given information in comparison with the latter, the new. Thus a cumulative given-new structure is formed. In Figure 3, the verbal definition of "napkin" (old information) is placed on the left while the picture (new information) is on the right because human beings usually read from left to right. In Figure 4, the verbal definition is old information on the top, and the picture is new information below it for we usually read from top to bottom. The information on the top is usually ideal, but that on the bottom is real, specific and detailed (Kress and Van Leeuwen 1996: 186). But a picture 
may distract the reader's attention from the verbal definition, so the reading path is not necessarily from left to right, and from top to bottom.

Non-verbal resources cohere into textual compositions in different ways. E-dictionaries can offer a layered, hierarchical inner access structure (as indicated by Figure 5 and Figure 6). If the user selects a particular sense from the menu displayed at the top of the entry (Tono 2000: 855; Lew 2011), the space for a specific definition can be adapted flexibly to the user need. This type of layered presentation embodies the role of the medium in developing and altering patterns of electronic dictionary consultation as well as its effects on language reception, production, and learning (Dziemianko 2012: 321).

Furthermore, the interconnections between different pieces of information, including the ubiquitous hyperlinks and internal links to word-processing applications allow users to copy text from dictionary to document.

\subsection{Time}

The last dimension is time. E-dictionaries can renew its information more frequently and easily than their print counterparts. This can help guarantee the recency and accuracy of meaning which prove to be the major concerns of users (Müller-Spitzer et al. 2012). For instance, some online dictionaries let users help update and add new senses to an entry.

In addition, the users' consultation history can be recorded. The use of cookies, i.e. small text files stored on the user's hard drive, allows the server to uniquely identify a returning visitor (De Schryver and Joffe 2006: 69; Verlinde and Peeters 2012: 150). This inherently helps build the semantic network in the user's mind during the process of learning.

In brief, multimodal definitions can extend the meaning system chronically for the sustainable development of (e-)dictionaries. In essence multimodal definition is dynamic and vigorous.

\section{Future directions for research}

Much recent literature has shown us two future directions for research: user studies and database construction, which is evidenced by the 2014 special issue of the International Journal of Lexicography, Using Online Dictionaries (Müller-Spitzer 2014) and Electronic Lexicography (Granger and Paquot 2012), etc. In the field of multimodal lexicography, further explorations of such critical areas as mode selection and intermodal synergy should be made in these two directions.

\subsection{User research}

E-dictionary user research has attracted a lot of attention recently, but there is still much work to do (Tarp 2009; Nesi 2013; Lew and Schryver 2014). While dictionary use has moved dynamically into the digital medium, user research 
on digital dictionaries has been somewhat slow in coming (Lew 2015). Lew (2010) points out factors to be considered in the design of multimodality, including dictionary culture, consultation goals and context, language proficiency level in general and in the specialized domain, and type of the lexical item to be defined.

The methods of investigating user studies are various. Welker (2010) identifies six of them: questionnaire surveys, interviews, observation, tests and experiments, protocols and log files. New laboratory-based methods have enabled researchers to observe in detail the way users interact with dictionary information on the computer screen (Nesi 2013). Representative examples are eye-tracking techniques from the cognitive science and psycholinguistics (e.g. Kaneta 2011; Simonsen 2011; Tono 2011; Lew et al. 2013) and usability testing methods from the information science (Heid and Zimmermann 2012). In the future, neuro-cognitive methods may be introduced, like Event-Related Potentials and Functional Magnetic Resonance Imaging, to explore how the mind works during dictionary consultations. Those advanced techniques can reveal microscopic aspects of dictionary use that probably cannot be discovered by behavioral observations or experiments.

In fact, previous user studies have shown different or even contradictory findings, such as those on the relationship between dictionary users' strategies and language learning (Gavriilidou 2013). Such variation of results may not be as contradictory as they seem, if we consider that the differences found could be attributed to the lack of investigations into the stratification of dictionary users. No previous research, however, has stressed the importance of such investigations. User classification, especially the one disclosing the latent or underlying classes among users, may serve as a mediating or moderating variable in related quantitative studies, including those aimed at optimizing the design of multimodal resources. A holistic analysis of these resources should consider the diversity of modes and submodes involved in meaning making while adopting a dynamic perspective on the users' cognitive processes and their taxonomy.

\subsection{Multimodal corpora}

Multimodal corpora in line with lexical databases, if annotated in the auditoryvisual domains, can provide useful resources for dictionary making in automated processes.

Online data mining seems to be indispensable to the construction of multimodal corpora. Fujii and Ishikawa (2005) proposed a method for searching the Web, seeking images associated with a specific word sense to generate content for multimedia encyclopedias. A particularly convincing implementation of the effective visualization of semantic relations is the VISUWORDS interface (www.visuwords.com), serving as a front-end to English WordNet data (Lew 2010). 
Unfortunately, annotating multimodal data is still problematic for both theoretical and technical reasons: first, there is a lack of linguistic and cognitive theories taking into consideration all the different aspects of multimodality; second, we need to specify a standardized way of representing multimodal information in order to give access to large multimodal corpora, as richly annotated as possible (Blache et al. 2009). So there is still a long way to go in this field.

\section{Conclusion}

In summary, a holistic view of meaning and a systemic-functional approach to the semiotic system have been adopted to broaden the horizons of e-dictionary definitions. Located at the intersection of multimodal discourse analysis and dictionary definition, multimodal definition is characterized by:

1) one key relationship (between multimodal devices and defining effect);

2) two key words (multimodality and definition) and two dominant variables (mode selection and intermodal synergy);

3) three metafunctions (ideational, interpersonal and textual);

4) four dimensions of meaning multiplication (content, form, space and time).

The three research questions raised at the beginning of the article have been answered. We think multimodal definition deserves its own place within the framework of multimodal lexicography since both practical and theoretical rationales support the necessity of having this new term. Only with proper mode selection and optimal intermodal synergy, can a robust semantic ecology be maintained in a multimodal definition. As it multiplies meaning in content, form, space and time, multimodal definition has great potential for transcending the limitations of verbal definitions and alleviating the meaning representation problems in current e-dictionaries. It would usher e-lexicography to a new era if the present theoretical and technical challenges could be overcome.

This study was inspired by and based on the pioneering work of Lew (2010). By examining online dictionaries, his trichotomy of multimodal devices was refined, with some new submodes added. Furthermore, a new type of intermodal synergy, (multimodal) metonymy, was found in e-dictionaries, complementing previous research in the field of multimodal discourse analysis with lexicographical evidence.

All these findings have cast some light on the construction of a theoretical model for e-lexicography, but the current study has its limitations for being largely dependent on retrospective analysis. A detailed plan was not worked out on systematic investigations into mode selection and intermodal synergy in multimodal definitions. This leaves much room for future work. It should also be noted that, to build a complete theoretical system of multimodal lexicography, another important subfield, multimodal exemplification, might be explored in 
line with multimodal definition.

\section{Notes}

1. Multimodal discourse analysis (MDA) is an emerging paradigm in discourse studies which extends the study of language per se to the study of language in combination with other resources, such as images, scientific symbolism, gesture, action, music and sound (O'Halloran 2011: 120).

2. Framing is the use of boundaries connecting or disconnecting one space from another (Van Leeuwen 2005: 18).

3. A floating tip is a temporary window (usually small) indicating the meaning or translation etc. of a word/phrase and emerging only when the mouse rests on it.

4. A cover term "elaboration" is used for all the types by some researchers (cf. Unsworth 2006, 2008; Painter and Martin 2011).

\section{Acknowledgements}

I would like to express my deep gratitude to Prof. Yihua Zhang and Dr. Liang Li of Guangdong University of Foreign Studies (GDUFS) for their discussions about dictionary definitions. I am greatly indebted to Prof. Gunther Kress, Prof. Len Unsworth, Dr. Francis Low and Dr. Yiqiong Zhang for their talks at the forums on multiliteracies hosted by GDUFS and the Hong Kong Polytechnic University in 2014 and 2015. Special thanks are also due to Dr. Dongping Zheng of the University of Hawai'i at Mānoa and the anonymous reviewers for their comments and suggestions on earlier drafts of the article.

\section{Bibliography}

\section{A. Dictionaries}

CDO. Cambridge Dictionaries Online. http://dictionary.cambridge.org.

LDOCE. Online Longman Dictionary of Contemporary English. http://www.ldoceonline.com/dictionary. MWVD. Online Merriam-Webster Visual Dictionary. http://visual.merriam-webster. com.

OALD. Wehmeier, Sally (Ed.). 2000. Oxford Advanced Learner's Dictionary of Current English. Sixth edition. Oxford: Oxford University Press.

OLD. Oxford Learner's Dictionary. http://www.oxfordlearnersdictionaries.com.

VISUWORDS. VISUWORDS Online Graphical Dictionary. http://visuwords.com.

VT. Visual Thesaurus. http://www.visualthesaurus.com.

\section{B. Other references}

Adamska-Sałaciak, Arleta. 2008. Prepositions in Dictionaries for Foreign Learners: A Cognitive Linguistic Look. Bernal, E. and J. DeCesaris (Eds.). 2008. Proceedings of the XIII EURALEX International Congress, Barcelona, 15-19 July 2008: 1477-1485. Sèrie Activitats 20. Barcelona: 
Universitat Pompeu Fabra, Institut Universitari de Lingüística Aplicada.

Amsler, Robert. 2012. The Future of Our Field. http://www.freelists.org/post/euralex/The-futureof- our-field-Part-1.

Atkins, B.T. Sue and Michael Rundell. 2008. The Oxford Guide to Practical Lexicography. Oxford/ New York: Oxford University Press.

Blache, Philippe, Roxane Bertrand and Gaëlle Ferré. 2009. Creating and Exploiting Multimodal Annotated Corpora: The ToMA Project. Kipp, Michael, Jean-Claude Martin, Patrizia Paggio and Dirk Heylen (Eds.). 2009. Multimodal Corpora: From Models of Natural Interaction to Systems and Applications: 38-53. Berlin/Heidelberg: Springer-Verlag.

Bulling, Andreas and Hans Gellersen. 2010. Toward Mobile Eye-Based Human-Computer Interaction. IEEE Pervasive Computing 9(4): 8-12.

Caruso, Valeria. 2014. Key Issues in Fuertes-Olivera and Tarp's Theory and Practice of Specialised Online Dictionaries. Lexikos 24: 362-377.

Chan, Eveline. 2011. Integrating Visual and Verbal Meaning in Multimodal Text Comprehension: Towards a Model of Intermodal Relations. Dreyfus, Shoshana, Susan Hood and Maree Stenglin (Eds.). 2011. Semiotic Margins: Meaning in Multimodalities: 144-167. London: Continuum.

Chen, Yuzhen. 2010. Dictionary Use and EFL Learning. A Contrastive Study of Pocket Electronic Dictionaries and Paper Dictionaries. International Journal of Lexicography 23(3): 275-306.

Coffey, Stephen. 2006. High-frequency Grammatical Lexis in Advanced-level English Learners' Dictionaries: From Language Description to Pedagogical Usefulness. International Journal of Lexicography 19(2): 157-173.

De Schryver, Gilles-Maurice and David Joffe. 2006. The Users and Uses of TshwaneLex One. De Schryver, Gilles-Maurice (Ed.). 2006. DWS 2006: Proceedings of the Fourth International Workshop on Dictionary Writing Systems, Turin, Italy, 5 September 2006: 41-46. Pretoria: (SF)2 Press.

Dziemianko, Anna. 2012. On the Use(fulness) of Paper and Electronic Dictionaries. Granger, Sylviane and Magali Paquot (Eds.). 2012: 319-342.

Feng, Chunbo. 2009. Research on Pictorial Illustrations in English Dictionaries. Shanghai: The Press of East China University of Science and Technology.

Fuertes-Olivera, Pedro A. and Sven Tarp. 2014. Theory and Practice of Specialised Online Dictionaries. Berlin: De Gruyter Mouton.

Fujii, Atsushi and Tetsuya Ishikawa. 2005. Toward the Automatic Compilation of Multimedia Encyclopedias: Associating Images with Term Descriptions on the Web. Proceedings of the 2005 IEEE/WIC/ACM International Conference on Web Intelligence, Compiegne, France, 19-22 September 2005: 536-542. Washington, DC: IEEE Computer Society.

Gavriilidou, Zoe. 2013. Development and Validation of the Strategy Inventory for Dictionary Use (SIDU). International Journal of Lexicography 26(2): 135-153.

Gill, Talia. 2002. Visual and Verbal Playmates: An Exploration of Visual and Verbal Modalities in Children's Picture Books. Unpublished. Sydney: University of Sydney.

Gouws, Rufus H. 2014. Article Structures: Moving from Printed to e-Dictionaries. Lexikos 24: 155-177.

Granger, Sylviane and Magali Paquot (Eds.) 2012. Electronic Lexicography. Oxford: Oxford University Press.

Halliday, Michael. 1985. An Introduction to Functional Grammar. London: Edward Arnold.

Heid, Ulrich and Jan Timo Zimmermann. 2012. Usability Testing as a Tool for e-Dictionary Design: Collocations as a Case in Point. Fjeld, Ruth Vatvedt and Julie Matilde Torjusen (Eds.). 
2012. Proceedings of the 15th Euralex International Congress, 7-11 August 2012: 661-671. Oslo: Department of Linguistics and Scandinavian Studies, University of Oslo.

Kaneta, Taku. 2011. Folded or Unfolded: Eye-Tracking Analysis of L2 Learners' Reference Behavior with Different Types of Dictionary. Akasu, K. and S. Uchida (Eds.). 2011. Asialex 2011 Proceedings Lexicography: Theoretical and Practical Perspectives, 22-24 August 2011: 219-224. Kyoto: Asian Association for Lexicography.

Kress, Gunther. 2010. Multimodality: A Social Semiotic Approach to Contemporary Communication. New York: Routledge.

Kress, Gunther and Theo van Leeuwen. 1996. Reading Images: The Grammar of Visual Design. London: Routledge.

Kurtz, Lindsey M. 2012. Learning from Twenty-First Century Second Language Learners: A Case Study in Smartphone Use of Language Learners. M.A. Thesis. Ames, Iowa: Iowa State University.

Lemke, Jay L. 2002. Travels in Hypermodality. Visual Communication 1(3): 299-325.

Lew, Robert. 2010. Multimodal Lexicography: The Representation of Meaning in Electronic Dictionaries. Lexikos 20: 290-306.

Lew, Robert. 2011. Online Dictionaries of English. Fuertes-Olivera, Pedro A. and Henning Bergenholtz (Eds.). 2011. e-Lexicography: The Internet, Digital Initiatives and Lexicography: 230-250. London/New York: Continuum.

Lew, Robert. 2015. Research into the Use of Online Dictionaries. International Journal of Lexicography 28(2): 232-253.

Lew, Robert and Joanna Doroszewska. 2009. Electronic Dictionary Entries with Animated Pictures: Lookup Preferences and Word Retention. International Journal of Lexicography 22(3): 239-257.

Lew, Robert, Marcin Grzelak and Mateusz Leszkowicz. 2013. How Dictionary Users Choose Senses in Bilingual Dictionary Entries: An Eye-Tracking Study. Lexikos 23: 228-254.

Lew, Robert and Gilles-Maurice de Schryver. 2014. Dictionary Users in the Digital Revolution. International Journal of Lexicography 27(4): 341-359.

Lim, Victor Fei. 2004. Developing an Integrative Multi-Semiotic Model. O'Halloran, Kay (Ed.). 2004. Multimodal Discourse Analysis: Systemic Functional Perspectives: 220-246. London/New York: Continuum.

Luo, Yongsheng. 2012. A Tentative Study on Image-Word Definition in Multimodal English Learner's Dictionary. Journal of Guangxi University for Nationalities 34(1): 165-170.

Müller-Spitzer, Carolin (Ed.). 2014. Using Online Dictionaries. Lexicographica. Series Maior 145. Berlin: Walter de Gruyter.

Müller-Spitzer, Carolin, Alexander Koplenig and Antje Töpel. 2012. Online Dictionary Use: Key Findings from an Empirical Research Project. Granger, Sylviane and Magali Paquot (Eds.). 2012: 425-457.

Martinec, Radan and Andrew Salway. 2005. A System for Image-Text Relations in New (and Old) Media. Visual Communication 4(3): 337-371.

Nesi, Hilary. 2010. The Virtual Vocabulary Notebook: The Electronic Dictionary as Vocabulary Learning Tool. Blue, George (Ed.). 2010. Developing Academic Literacy: 213-226. Oxford: Peter Lang.

Nesi, Hillary. 2012. Alternative e-Dictionaries: Uncovering Dark Practices. Granger, Sylviane and Magali Paquot (Eds.). 2012: 363-378.

Nesi, Hilary. 2013. Researching Users and Uses of Dictionaries. Jackson, Howard (Ed.). 2013. The Bloomsbury Companion to Lexicography: 62-74. London: Bloomsbury. 
Ogden, Charles Kay and Ivor Armstrong Richards. 1923. The Meaning of Meaning. A Study of the Influence of Language upon Thought and of the Science of Symbolism. London: Routledge and Kegan Paul.

O'Halloran, Kay L. 2008. Systemic Functional-Multimodal Discourse Analysis (SF-MDA): Constructing Ideational Meaning Using Language and Visual Imagery. Visual Communication 7(4): 443-475.

O'Halloran, Kay L. 2011. Multimodal Discourse Analysis. Hyland, K. and B. Paltridge (Eds.). 2011. Companion to Discourse: 120-137. London/New York: Continuum.

Painter, Clare and James Martin. 2011. Intermodal Complementarity: Modelling Affordances across Verbiage and Image in Children's Picture Books. Huang, Guo Wen (Ed.). 2011. Studies in Functional Linguistics and Discourse Analysis: 132-158. Beijing: Higher Education Press.

Painter, Clare, James R. Martin and Len Unsworth. 2013. Reading Visual Narratives: Image Analysis of Children's Picture Books. London: Equinox.

Prinsloo, Danie J. 2012. Electronic Lexicography for Lesser-resourced Languages: The South African Context. Granger, Sylviane and Magali Paquot (Eds.). 2012: 119-144.

Rosch, Eleanor. 1973. Natural Categories. Cognitive Psychology 4(3): 328-350.

Royce, Terry. 1998. Synergy on the Page: Exploring Intersemiotic Complementarity in Page-Based Multimodal Text. JASFL Occasional Papers 1(1): 25-49.

Royce, Terry. 2007. Intersemiotic Complementarity: A Framework for Multimodal. Royce, Terry and Wendy Bowcher (Eds.). 2007. New Directions in the Analysis of Multimodal Discourse: 63109. Mahwah, NJ: Lawrence Erlbaum.

Simonsen, Henrik Køhler. 2011. User Consultation Behaviour in Internet Dictionaries: An EyeTracking Study. Hermes 46: 75-101.

Tarp, Sven. 2008. Lexicography in the Borderland between Knowledge and Non-knowledge: General Lexicographical Theory with Particular Focus on Learner's Lexicography. Tübingen: Max Niemeyer.

Tarp, Sven. 2009. Reflections on Lexicographical User Research. Lexikos 19: 275-296.

Thibault, Paul J. 2001. Multimodality and the School Science Textbook. Torsello, Carol Taylor, Giuseppe Brunetti and Nicoletta Penello (Eds.). 2001. Corpora Testuali per Ricerca, Traduzione e Apprendimento Linguistico: 293-335. Padua: Unipress.

Tono, Yukio. 2000. On the Effects of Different Types of Electronic Dictionary Interfaces on L2 Learners' Reference Behaviour in Productive/Receptive Tasks. Heid, U., S. Evert, E. Lehmann and C. Rohrer (Eds.). 2000. Proceedings of the Ninth EURALEX International Congress, EURALEX 2000, Stuttgart, Germany, 8-12 August 2000: 855-862. Stuttgart: Institut für Maschinelle Sprachverarbeitung, Universität Stuttgart.

Tono, Yukio. 2009. Pocket Electronic Dictionaries in Japan: User Perspectives. Bergenholtz, H., S. Nielsen and Sven Tarp (Eds.). 2009. Lexicography at a Crossroads. Dictionaries and Encyclopedias Today, Lexicographical Tools Tomorrow: 33-67. Bern: Peter Lang.

Tono, Yukio. 2011. Application of Eye-Tracking in EFL Learners' Dictionary Look-up Process Research. International Journal of Lexicography 24(1): 124-153.

Unsworth, Len. 2006. Towards a Metalanguage for Multiliteracies Education: Describing the Meaning-Making Resources of Language-Image Interaction. English Teaching: Practice and Critique 5(1): 55-76.

Unsworth, Len. 2008. Multiliteracies and Metalanguage: Describing Image/Text Relations as a Resource for Negotiating Multimodal Texts. Coiro, Julie, Michele Knobel, Colin Lankshear 
http://lexikos.journals.ac.za

and Donald J. Leu (Eds.). 2008. Handbook of Research on New Literacies: 377-406. Mahwah, NJ: Lawrence Erlbaum.

Van Leeuwen, Theo. 2005. Introducing Social-Semiotics. London/New York: Routledge.

Verlinde, Serge and Geert Peeters. 2012. Data Access Revisited: The Interactive Language Toolbox. Granger, Sylviane and Magali Paquot (Eds.). 2012: 147-162.

Welker, Herbert Andreas. 2010. Dictionary Use: A General Survey of Empirical Studies. Brasilia. Author's edition: An updated English version of Welker's earlier monograph, published in 2006 under the title $O$ uso de dicionários: Panorama geral das pesquisas empiricas (reviewed by Lew, R., in 2007 in International Journal of Lexicography 20(4): 401-403).

Wittgenstein, Ludwig. 1953. Philosophical Investigations. Edited by Anscombe, G.E.M. and R. Rhees. Oxford: Blackwell.

Yang, Xinzhang. 2012. Text-image Relations in Learner's English-Chinese Dictionaries. Journal of University of Science and Technology Beijing (Social Sciences Edition) 28(4): 45-51.

Zhang, Ping. 2004. Is the Electronic Dictionary Your Faithful Friend? CELEA Journal 27(2): 23-28.

Zhang, Yihua. 2002. Semantics and Lexicographical Definition. Shanghai: Shanghai Lexicographical Publishing House.

Zhang, Yihua. 2015. Second Language Acquisition and Learner's Dictionaries. Beijing: The Commercial Press. 